\title{
Critical evaluation of the efficacy and tolerability of azilsartan
}

This article was published in the following Dove Press journal:

Vascular Health and Risk Management

12 May 2012

Number of times this article has been viewed

\author{
Alberto R De Caterina ${ }^{1,2}$ \\ Andrew R Harper ${ }^{2,3}$ \\ Florim Cuculi ${ }^{2}$ \\ 'Istituto Scienze della Vita, Scuola \\ Superiore Sant'Anna, Pisa, Italy; \\ ${ }^{2}$ Oxford University Hospitals, \\ Oxford; ${ }^{3}$ Faculty of Medical Sciences, \\ Newcastle University, Newcastle upon \\ Tyne, United Kingdom
}

\begin{abstract}
Appropriate control of blood pressure (BP) in hypertensive patients still represents the major therapeutic goal in the treatment of hypertension. Despite the growing attention and wide range of antihypertensive agents available in the clinical scenario, the target of BP below the advised thresholds of 140/90 $\mathrm{mmHg}$ is, unfortunately, often unreached. For this reason, the search for new antihypertensive agents is still ongoing. Azilsartan medoxomil, a new angiotensin receptor blocker that has been recently introduced in the clinical arena, represents the eighth angiotensin receptor blocker currently available for BP control. The aim of this paper is to describe the efficacy and safety profile of this new compound, reviewing available data obtained from both pre-clinical and clinical studies.
\end{abstract}

Keywords: azilsartan medoxomil, angiotensin receptor blocker, hypertension

\section{Introduction}

Chronically elevated blood pressure (BP) is a highly heterogeneous, complex disease and a major global health issue. ${ }^{1}$ Hypertension affects approximately one quarter of the world's adult population, and is predicted to increase in prevalence alongside the urbanization of economically developing countries. ${ }^{2,3}$ Hypertension has been recognized by the World Health Organization as the leading cause of global mortality, accounting for 7.6 million deaths and 92 million disability-adjusted life-years worldwide. ${ }^{4,5}$ Such sinister statistics are reflected in cardiovascular data showing that two-thirds of all cerebrovascular disease cases and $50 \%$ of all ischemic heart disease cases are attributable to non-optimal BP. ${ }^{5,6}$

Among the many antihypertensive agents, drugs that modulate the renin-angiotensin-aldosterone system (RAAS) are more commonly used because of their efficacy and their excellent tolerability profile. Specifically, those agents able to inhibit the action of angiotensin II by binding directly to the angiotensin type $1\left(\mathrm{AT}_{1}\right)$ receptor, such as angiotensin receptor blockers (ARBs), are the most tolerated. ${ }^{7}$ In addition, aside from their well-known renoprotective effects, ${ }^{8,9}$ some ARBs have shown efficacy in reducing mortality in patients with heart failure and post-myocardial infarction. ${ }^{10-12}$

For these reasons, the search for novel antihypertensive agents - a novel ARB in particular - is still ongoing. The aim of this review is to focus attention on a novel ARB recently introduced in the clinical arena: azilsartan medoxomil.

De Caterina

Istituto di Scienze della Vita, Scuola

Superiore Sant'Anna, Piazza Martiri della

Libertà, 56I27 Pisa, Italy

Tel +39050883 III

Fax +39050883225

Email adecatro@yahoo.it

\section{Why and how we need to target the RAAS system}

The pathophysiology of essential hypertension is complex and, although genomewide association studies have delineated multiple common variants associated 
with essential hypertension, no firm hypothesis has yet been established. ${ }^{13}$ Multiple signaling pathways regulating BP have previously been elicited through physiological experiments. Of these, the discovery and accurate characterization of the neurohumoral pathway of the RAAS has enabled the production of pharmacological agents that assist in reducing a patient's BP. ${ }^{14}$ Figure 1 recapitulates the RAAS. Briefly, the RAAS cascade converts angiotensinogen to angiotensin II through an intermediate substrate, angiotensin I. The rate-limiting step within the cascade requires renin, a hormone synthesized and released from juxtaglomerular cells within the kidney's afferent arterioles, to convert angiotensinogen to angiotensin I. ${ }^{14}$ Angiotensin I is then enzymatically converted into angiotensin II, a pleiotropic hormone able to target the angiotensin type 1 receptor $\left(A T_{1} R\right)$, which is located throughout the vasculature of multiple organs. ${ }^{14}$ Angiotensin II causes systemic vasoconstriction, increased sympathetic output, increased arginine vasopressin production, and increased aldosterone release. Consequently, an increase in angiotensin II results in increased peripheral vascular resistance, fluid retention, and increased cardiac output, thus contributing to elevated BP.

The conversion of angiotensin I to angiotensin II is mediated by the angiotensin converting enzyme (ACE). Competitive inhibition of the ACE, a relatively non-specific enzyme, with ACE inhibitors can assist in reducing BP. Metaanalysis demonstrated a reduction in both systolic and diastolic pressures in patients with essential hypertension, with a mean reduction of $6-9 \mathrm{mmHg}$ and a $4-5 \mathrm{mmHg}$, respec- tively. ${ }^{15}$ Despite these advantages, some limitations exist relating to ACE inhibitors. On one hand, substrate accumulation of renin and angiotensin I may attenuate the desired blockade. On the other hand, concomitant tachykinin accumulation frequently incites side effects, including dry cough and angioedema, thus reducing the compliance of the patient with respect to its prescribed regimen, which in turn contributes to sub-optimal BP control. In addition, angiotensin II formation is not entirely dependent upon the action of the ACE, with formation occurring through alternative pathways.

To overcome the limitations of ACE inhibitors, the strategy to directly inhibit the binding of angiotensin II to the $\mathrm{AT}_{1} \mathrm{R}$ through ARBs has been shown to provide an effective pharmacologic strategy for inhibiting the $\mathrm{AT}_{1} \mathrm{R}$ and diminishing angiotensin II-derived effects, through both ACE-dependent and alternate pathways. ${ }^{14}$ Eight ARBs (losartan, valsartan, candesartan, irbesartan, olmesartan, telmisartan, eprosartan, and azilsartan) have been approved for the treatment of hypertension. Their main characteristics are summarized in Table 1. Clinically, ACE inhibitors and ARBs are prescribed interchangeably for the first-line treatment of hypertension. ${ }^{16}$

In addition to ACE inhibitors and ARBs, there is an increasing number of additional agents, which modulate the RAAS, to lower BP and prevent cardiovascular events, including aldosterone antagonists, renin inhibitors, and neutral endopeptidase inhibitors. ${ }^{17-19}$ As this specific review will focus on azilsartan medoxomil, we refer the reader to specifically focused articles..$^{20-24}$

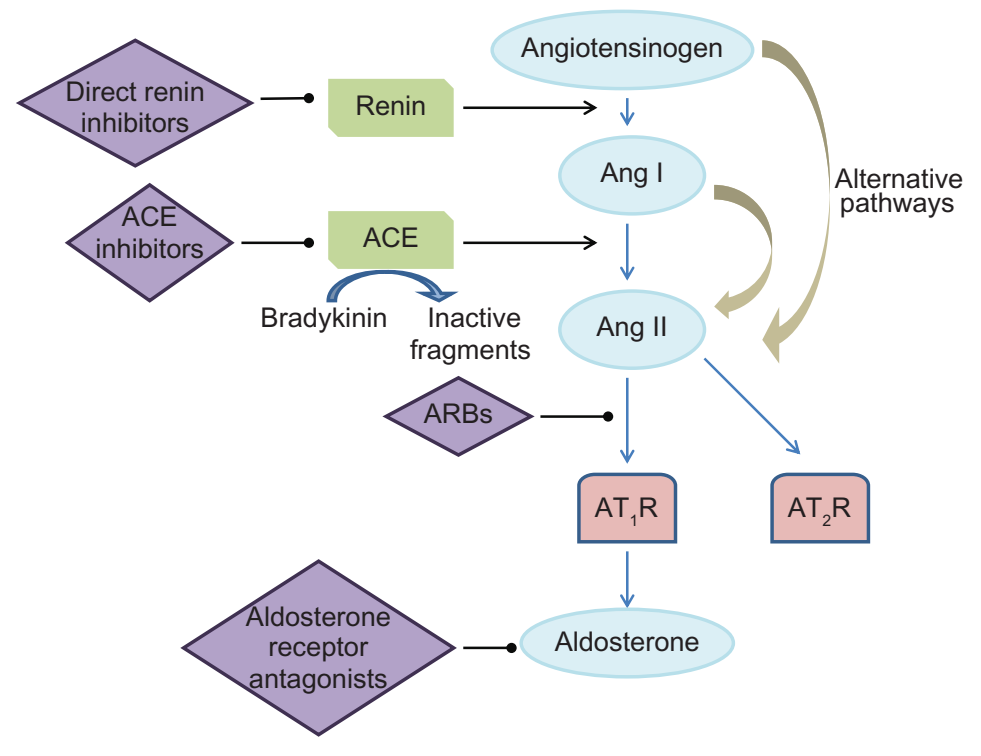

Figure I The renin-angiotensin-aldosterone system. 


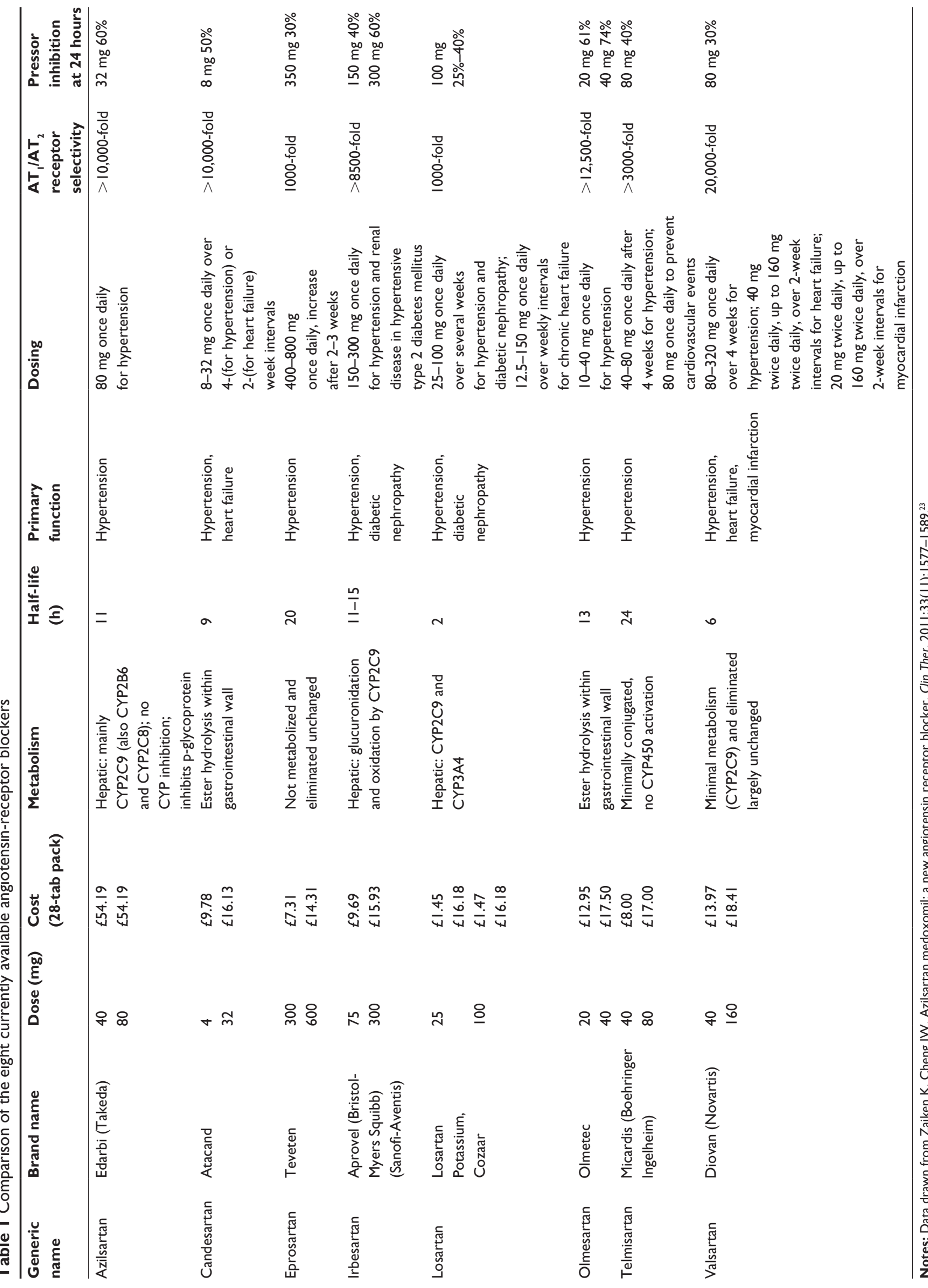




\section{Azilsartan medoxomil: pharmacodynamic and pharmacokinetic profile}

Following the introduction in the clinical arena of azilsartan medoxomil in early 2011, eight ARBs are now recognized in Europe and by the United States Food and Drug Administration for the treatment of hypertension.

\section{Mechanism of action}

Azilsartan medoxomil (previously named TAK-491), an orally administered prodrug, has recently become the eighth ARB to achieve Food and Drug Administration approval for the treatment of hypertension. Following oral administration, azilsartan medoxomil is hydrolyzed into azilsartan (TAK-536) in both the gastrointestinal tract and plasma. ${ }^{25}$ Azilsartan, a selective $\mathrm{AT}_{1} \mathrm{R}$ antagonist, prevents angiotensin II binding, specifically within vascular, smooth muscles and the adrenal gland, and produces vasodilation and attenuated aldosterone effects. ${ }^{26}$ Azilsartan and candesartan are structurally very similar, which may explain their similar AT ${ }_{1}$ affinity. Indeed, azilsartan is a highly selective antagonist for $\mathrm{AT}_{1} \mathrm{R}$, exhibiting a $>10,000$-fold higher affinity for the $\mathrm{AT}_{1}$ receptor than for the $\mathrm{AT}_{2}$ receptor. ${ }^{24}$ This effect is significant; however, valsartan, olmesartan, and candesartan all demonstrate equivalent or greater $\mathrm{AT}_{1}$ selectivity (see Table 1). The manufacturer suggests that the antihypertensive effect of azilsartan is not disrupted by renin secretion fluctuations, primarily due to its $\mathrm{AT}_{1} \mathrm{R}$ inhibition. ${ }^{26}$

\section{Pharmacokinetics}

Azilsartan achieves its peak plasma concentration 1.5 to 3 hours following oral administration, with bioavailability (approximately 58\%) unaffected by co-administration with food. Azilsartan demonstrates a half-life of approximately 11 hours and achieves a steady-state concentration 5 days following consecutive oral administration. ${ }^{25,26}$ Reports from healthy subjects suggest that the volume of distribution is approximately $30 \mathrm{~L}$, with $>99 \%$ circulating attached to plasma proteins. ${ }^{25,26}$

Azilsartan metabolism occurs mainly via the hepatic cytochrome P450, with no CYP system induction or inhibition properties. Azilsartan does, however, inhibit p-glycoprotein, an efflux transporter. A major inactive metabolite (MI) forms through CYP2C9, while an additional minor, inactive metabolite (MII) is generated through CYP2B6 and CYP2C8. The MII has approximately $50 \%$ systemic exposure, and MI has $<1 \%$ systemic exposure. ${ }^{21,23}$

Azilsartan's inactive metabolites (MI and MII) are excreted by the kidney at a rate of $2.3 \mathrm{~mL} / \mathrm{min}$. Animal studies recording 14C-radiolabeled orally administered azilsartan recovered approximately $97 \%$ of the administered dose within 14 days. Specifically, 55\% was traced to fecal excretion, and urine accounted for $42 \%$, of which $15 \%$ was excreted as azilsartan. ${ }^{23}$

Although no studies regarding the pharmacokinetics of azilsartan are currently available on the PubMed website, the manufacturer has made available data reporting a dose proportionality following single- and multiple-dosing of azilsartan in the dose range of 20-320 mg. According to singleand multiple-dose pharmacokinetic studies, $\mathrm{AUC}$ and $\mathrm{C}_{\max }$ are both modestly affected by age, sex, race, renal impairment (mild, moderate, severe, or end-stage renal disease), and hepatic impairment, although the pharmacokinetic properties of azilsartan have not been studied in patients with severe hepatic impairment. Accordingly, no dosage adjustment of azilsartan is suggested on the basis of a patient's age, gender, race, or degree of renal/hepatic impairment. ${ }^{25}$

As with current ARBs, it is inadvisable to prescribe azilsartan during the first, second, or third trimesters of pregnancy. Although human studies have not been conducted, evidence has been gleaned from low levels of azilsartan being detected in lactating rats' milk.

\section{Drug interactions}

No major drug interaction studies on azilsartan have been reported to date; however, the manufacturer reports no significant pharmacokinetic disruptions for numerous drugs combined with either 40-mg or 80-mg doses of azilsartan. Drug interactions with a daily $80-\mathrm{mg}$ azilsartan dose were investigated in 36 healthy volunteers against concomitant administration of a $\mathrm{P} 450$ probe cocktail (including $30 \mathrm{mg}$ of dextromethorphan, $500 \mathrm{mg}$ of tolbutamide, $200 \mathrm{mg}$ of caffeine, $4 \mathrm{mg}$ of midazolam, and $60 \mathrm{mg}$ of fexofenadine) or coadministration with an antacid or oral digoxin. ${ }^{25}$ Similarly, an orally administered $40 \mathrm{mg}$ dose of azilsartan was investigated in 36 healthy volunteers, with concomitant delivery of warfarin, glyburide, metformin pioglitazone, chlorthalidone, and amlodipine. No significant pharmacokinetic or international normalized ratio differences were in evidence. ${ }^{25}$

In addition, 36 healthy volunteers undertook a drug interaction study investigating $40 \mathrm{mg}$ doses of azilsartan with co-administration of either $200 \mathrm{mg}$ of fluconazole (a CYP2C9 inhibitor) or $400 \mathrm{mg}$ of ketoconazole (a CYP3A4/5 inhibitor). The study described how concomitant CYP2C9 inhibition causes reduced renal clearance and increased the AUC by approximately $40 \%{ }^{25}$ Concomitant CYP3A4/5 inhibition reduced the AUC by approximately $20 \%$. 
This initial study requires further investigation to fully evaluate the true clinical significance of this interaction.

Although no evidence specifically evaluating azilsartan with nonsteroidal anti-inflammatory agents or cyclooxygenase- 2 inhibitors exists, Takeda issued a warning about their combined usage with azilsartan. ${ }^{26}$ This concern stems from knowledge regarding non-steroidal anti-inflammatory agents and cyclooxygenase- 2 inhibitors contributing to acute pre-renal failure through prostaglandins inhibition and a reduced glomerular filtration rate.

\section{Preclinical trials}

Preclinical studies have demonstrated that azilsartan is superior to alternative ARBs (ie, valsartan and olmesartan) in lowering 24-hour BP. Current evidence suggests that this response is due to its property of high affinity and slow dissociation to $\mathrm{AT}_{1} \mathrm{R}$. This characteristic attenuates angiotensin II-derived effects more persistently than previous ARBs, leading to a prolonged functional effect. ${ }^{24,27}$

Aside from blocking $\mathrm{AT}_{1} \mathrm{R}, \mathrm{ARBs}$ have been shown to provide additional benefits in cardiovascular protection, and preclinical studies have investigated the pleiotropic effects of this new compound, in addition to BP control. Many of the functional effects demonstrated by azilsartan are dependent on two key factors relating to the molecule: its high affinity and slow dissociation from $\mathrm{AT}_{1} \mathrm{R}$, and its inverse agonistic properties. These factors make azilsartan a unique option as a possible therapeutic agent in a wide range of angiotensin II-dependent cardiometabolic diseases. These include cardiac hypertrophy, unstable atherosclerotic plaque, cardiac fibrosis, insulin resistance, and renoprotection.

Several studies have investigated the anti-proliferative properties of azilsartan within vascular endothelial cells compared to traditional ARBs. Azilsartan has been shown to be superior in inhibiting the proliferation of rabbit aortic endothelial cells compared to valsartan. Interestingly, the anti-proliferative properties demonstrated by azilsartan can be established at plasma concentrations of $1 \mu \mathrm{mol} / \mathrm{L}$, similar to human oral drug-dosing concentrations. ${ }^{24}$ The mechanism attenuating proliferation is not entirely $\mathrm{AT}_{1} \mathrm{R}$ dependent, and it has been suggested that the pleiotropic effects are largely attributable to azilsartan's inverse agonist properties. These inverse agonist properties are clinically relevant, as they could enable a new generation of ARBs, including azilsartan, to prevent cardiac hypertrophy.

Investigators have also demonstrated that azilsartan can stabilize atherosclerotic plaque and reduce cardiac fibrosis formation following myocardial infarction in mice.
Specifically, it has been proposed that azilsartan suppresses the angiotensin II-mediated plasminogen activator inhibitor type-1, causing increased collagen deposition, thus stabilizing atherosclerotic plaque. ${ }^{28}$

Hypertension is associated with insulin resistance, possibly due to excess angiotensin II. Candesartan has previously demonstrated improved insulin sensitivity in hypertensive patients. ${ }^{29}$ Investigators have determined that azilsartan also demonstrates improved insulin sensitivity in rats, mice, and dogs in a superior fashion to olmesartan..$^{30,31}$ Debates continue, however, regarding how ARBs generate this effect.

Finally, patients with metabolic syndrome have a poorer prognosis if there is documented proteinuria. ${ }^{32,33}$ Traditional ARBs have previously been shown to benefit the diabetic population, mainly offering a renoprotective effect related to a reduction of proteinuria. ${ }^{10}$ Azilsartan has been investigated in animal models with nephropathy, and Kusumoto et al showed azilsartan to be superior in reducing albuminuria in rats compared to olmesartan. ${ }^{31}$

The results from these pre-clinical trials are encouraging; however, validation and replication in humans is required. Azilsartan has demonstrates superior 24-hour control of systolic BP and offers a broad spectrum of possible clinical benefits associated with cardiometabolic disease, possibly making it superior to traditional ARBs.

\section{Clinical trials}

Several comparative studies have assessed the efficacy of azilsartan in the treatment of hypertension. In a double-blind, placebo-controlled trial of 1275 hypertensive patients, the efficacy of azilsartan was compared to placebo and olmesartan. The primary efficacy measure was the mean 24-hour ambulatory systolic pressure. The mean baseline systolic BP was $146 \mathrm{mmHg}$. Eighty-mg doses of azilsartan were more effective in reducing the mean 24-hour systolic pressure compared to $40 \mathrm{mg}$ of olmesartan (a mean difference of $2.1 \mathrm{mmHg}$ ). In terms of tolerability, azilsartan was very well tolerated, as the incidence of the most commonly reported adverse events (ie, headache, dyslipidemia, and dizziness) were reported to be similar compared to the placebo and candesartan groups. ${ }^{34}$

In another study of 1291 subjects, where the mean systolic BP before treatment was $145 \mathrm{mmHg}$, reduction was highest with $80 \mathrm{mg}$ of azilsartan $(-14.3 \mathrm{mmHg})$, compared to $320 \mathrm{mg}$ of valsartan $(-10.0 \mathrm{mmHg})$ and $40 \mathrm{mg}$ of olmesartan $(-11.7 \mathrm{mmHg}) .{ }^{35} \mathrm{BP}$ control and response rates were higher than those observed in the valsartan arm, with an absolute rate of approximately $10 \%$ of patients reaching an acceptable BP 
control according to actual guidelines. Again, the tolerability profile was not significantly different compared to $320 \mathrm{mg}$ of valsartan, especially with regard to the number of adverse events, including those that were life-threatening or simply lead to a discontinuation of the drug.

The superiority of azilsartan was also confirmed when compared to other sartans. In a recently published study, 622 hypertensive Japanese patients with moderate hypertension were randomized for treatment with azilsartan (20-40 mg od) or candesartan (8-12 mg od). Azilsartan was more effective in reducing sitting systolic and diastolic $\mathrm{BP}$ at 16 weeks and ambulatory BP at 14 weeks, with a similar safety profile. ${ }^{22}$ The study concludes by stating that once-daily azilsartan use provides a more-potent, 24-hour antihypertensive effect than does candesartan, but with an equivalent safety threshold.

In summary, clinical trials of azilsartan have so far demonstrated promising results, and this new substance has the potential to become a very valuable drug in the treatment of hypertension.

\section{Conclusion}

Azilsartan is a very recently approved ARB that is now available in the clinical arena for the treatment of hypertension. Compared to the maximum doses of three other ARBs (valsartan, olmesartan, and candesartan), azilsartan appears to be more efficacious in reducing BP, with a similar safety and tolerability profile. Azilsartan's very high affinity and slow dissociation from $\mathrm{AT}_{1} \mathrm{R}$, together with its inverse agonistic properties, make it a very attractive candidate for further pushing its clinical effects beyond simple BP control, potentially counteracting cardiac hypertrophy, cardiac fibrosis, and insulin resistance, together with improved renoprotection and atherosclerotic plaque stabilization. However, unlike other ARBs, azilsartan is not backed up by clinical data supporting its ability to affect improvement in cardiovascular outcomes and is not approved for situations in which other ARBs may be used, such as diabetic nephropathy or heart failure.

\section{Disclosure}

The authors report no conflicts of interest in this work.

\section{References}

1. Rosendorff C, Black HR, Cannon CP, et al. Treatment of hypertension in the prevention and management of ischemic heart disease: a scientific statement from the American Heart Association Council for High Blood Pressure Research and the Councils on Clinical Cardiology and Epidemiology and Prevention. Circulation. 2007;115(21):2761-2788.
2. Yusuf S, Reddy S, Ounpuu S, Anand S. Global burden of cardiovascular diseases: part I: general considerations, the epidemiologic transition, risk factors, and impact of urbanization. Circulation. 2001;104(22):2746-2753.

3. Kearney PM, Whelton M, Reynolds K, Muntner P, Whelton PK, He J. Global burden of hypertension: analysis of worldwide data. Lancet. 2005;365(9455):217-223.

4. Guilbert JJ. The world health report 2002 - reducing risks, promoting healthy life. Educ Health (Abingdon). 2003;16(2):230.

5. Lawes CM, Vander Hoorn S, Rodgers A; International Society of Hypertension. Global burden of blood-pressure-related disease, 2001. Lancet. 2008;371(9623):1513-1518.

6. Lawes CM, Vander Hoorn S, Law MR, Elliott P, MacMahon S, Rodgers A. Blood pressure and the global burden of disease 2000. Part II: estimates of attributable burden. J Hypertens. 2006;24(3):423-430.

7. Mancia G, De Backer G, Dominiczak A, et al. 2007 ESH-ESC Practice Guidelines for the Management of Arterial Hypertension: ESH-ESC Task Force on the Management of Arterial Hypertension. J Hypertens. 2007;25(9):1751-1762.

8. Pitt B, Segal R, Martinez FA, et al. Randomised trial of losartan versus captopril in patients over 65 with heart failure (Evaluation of Losartan in the Elderly Study, ELITE). Lancet. 1997;349(9054):747-752.

9. Lewis EJ, Hunsicker LG, Clarke WR, et al. Renoprotective effect of the angiotensin-receptor antagonist irbesartan in patients with nephropathy due to type 2 diabetes. N Engl J Med. 2001;345(12):851-860.

10. Brenner BM, Cooper ME, de Zeeuw D, et al. Effects of losartan on renal and cardiovascular outcomes in patients with type 2 diabetes and nephropathy. N Engl J Med. 2001;345(12):861-869.

11. McMurray J, Solomon S, Pieper K, et al. The effect of valsartan, captopril, or both on atherosclerotic events after acute myocardial infarction: an analysis of the Valsartan in Acute Myocardial Infarction Trial (VALIANT). J Am Coll of Cardiol. 2006;47(4):726-733.

12. Pfeffer MA, Swedberg K, Granger CB, et al. Effects of candesartan on mortality and morbidity in patients with chronic heart failure: the CHARM-Overall programme. Lancet. 2003;362(9386):759-766.

13. Ehret GB, Munroe PB, Rice KM, et al. Genetic variants in novel pathways influence blood pressure and cardiovascular disease risk. Nature. 2011;478(7367):103-109. doi:10.1038/nature10405.

14. Zaman MA, Oparil S, Calhoun DA. Drugs targeting the renin-angiotensinaldosterone system. Nat Rev Drug Discov. 2002;1(8):621-636.

15. Heran BS, Wong MM, Heran IK, Wright JM. Blood pressure lowering efficacy of angiotensin converting enzyme (ACE) inhibitors for primary hypertension. Cochrane Database Syst Rev. 2008;4:CD003823.

16. McManus RJ, Caulfield M, Williams B; National Institute for Health and Clinical Excellence. NICE hypertension guideline 2011: evidence based evolution. BMJ. 2012;344:e181. doi:10.1136/bmj.e181.

17. Maron BA, Leopold JA. Aldosterone receptor antagonists: effective but often forgotten. Circulation. 2010;121(7):934-939.

18. Musini VM, Fortin PM, Bassett K, Wright JM. Blood pressure lowering efficacy of renin inhibitors for primary hypertension: a Cochrane systematic review. J Hum Hypertens. 2009;23(8):495-502.

19. Cuculi F, Erne P. Combined neutral endopeptidase inhibitors. Expert Opin on Investig Drugs. 2011;20(4):457-463.

20. Kurtz TW, Kajiya T. Differential pharmacology and benefit/risk of azilsartan compared to other sartans. Vasc Health Risk Manag. 2012;8: $133-143$.

21. Jones JD, Jackson SH, Agboton C, Martin TS. Azilsartan medoxomil (Edarbi): the eighth angiotensin II receptor blocker. PT. 2011;36(10):634-640.

22. Rakugi H, Enya K, Sugiura K, Ikeda Y. Comparison of the efficacy and safety of azilsartan with that of candesartan cilexetil in Japanese patients with grade I-II essential hypertension: a randomized, doubleblind clinical study. Hypertens Res. 2012. doi:10.1038/hr.2012.8.

23. Zaiken K, Cheng JW. Azilsartan medoxomil: a new angiotensin receptor blocker. Clin Ther. 2011;33(11):1577-1589. 
24. Kajiya T, Ho C, Wang J, Vilardi R, Kurtz TW. Molecular and cellular effects of azilsartan: a new generation angiotensin II receptor blocker. J Hypertens. 2011;29(12):2476-2483.

25. Center for Drug Evaluation and Research [website on the Internet] Silver Spring, MD: NDA 200-796: Azilsartan medoxomil, Clinical Pharmacology and Biopharmaceutics Review(s). 2010. Available from: http://www.accessdata.fda.gov/drugsatfda_docs/nda/2011/200796 Orig1s000ClinPharmR.pdf. Accessed 1 April, 2012.

26. Edarbi.com [homepage on the Internet]. Two options to help lower blood pressure. Deerfield, IL: Takeda Pharmaceuticals America, Inc. 2012. Available from: http://www.edarbi.com/. Accessed 1 April, 2012.

27. Ojima $M$, Igata $H$, Tanaka $M$, et al. In vitro antagonistic properties of a new angiotensin type 1 receptor blocker, azilsartan, in receptor binding and function studies. J Pharmacol Exp Ther. 2011;336(3):801-808

28. French CJ, Zaman AK, Sobel BE. The angiotensin receptor blocker, azilsartan medoxomil (TAK-491), suppresses vascular wall expression of plasminogen activator inhibitor type-I protein potentially facilitating the stabilization of atherosclerotic plaques. J Cardiovasc Pharmacol. 2011;58(2):143-148.

29. Grassi G, Seravalle G, Dell'Oro R, et al. Comparative effects of candesartan and hydrochlorothiazide on blood pressure, insulin sensitivity, and sympathetic drive in obese hypertensive individuals: results of the CROSS study. J Hypertens. 2003;21(9):1761-1769.
30. Kusumoto K, Igata H, Ojima M, et al. Antihypertensive, insulinsensitising and renoprotective effects of a novel, potent and long-acting angiotensin II type 1 receptor blocker, azilsartan medoxomil, in rat and dog models. Eur J Pharmacol. 2011;669(1-3):84-93.

31. Zhao M, Li Y, Wang J, et al. Azilsartan treatment improves insulin sensitivity in obese spontaneously hypertensive Koletsky rats. Diabetes Obes Metab. 2011;13(12):1123-1129. doi:10.1111/j.1463-1326. 2011.01471.x.

32. Thomas G, Sehgal AR, Kashyap SR, Srinivas TR, Kirwan JP, Navaneethan SD. Metabolic syndrome and kidney disease: a systematic review and meta-analysis. Clin J Am Soc Nephrol. 2011;6(10):2364-2373.

33. Segura J, Campo C, Gil P, Roldán C, et al. Development of chronic kidney disease and cardiovascular prognosis in essential hypertensive patients. J Am Soc Nephrol. 2004;15(6):1616-1622.

34. Bakris GL, Sica D, Weber M, et al. The comparative effects of azilsartan medoxomil and olmesartan on ambulatory and clinic blood pressure. J Clin Hypertens (Greenwich). 2011;13(2):81-88. doi:10.1111/j. 1751-7176.2010.00425.x.

35. Sica D, White WB, Weber MA, et al. Comparison of the novel angiotensin II receptor blocker azilsartan medoxomil vs valsartan by ambulatory blood pressure monitoring. J Clin Hypertens (Greenwich) 2011;13(7):467-472. doi:10.1111/j.1751-7176.2011.00482.x.
Vascular Health and Risk Management

\section{Publish your work in this journal}

Vascular Health and Risk Management is an international, peerreviewed journal of therapeutics and risk management, focusing on concise rapid reporting of clinical studies on the processes involved in the maintenance of vascular health; the monitoring, prevention and treatment of vascular disease and its sequelae; and the involvement of

\section{Dovepress}

metabolic disorders, particularly diabetes. This journal is indexed on PubMed Central and MedLine. The manuscript management system is completely online and includes a very quick and fair peer-review system, which is all easy to use. Visit http://www.dovepress.com/ testimonials.php to read real quotes from published authors. 